\title{
Sediment classification in a Brazilian reservoir: Pros and cons of parametric low frequencies
}

\author{
Klajdi Sotiri, Stephan Hilgert, Stephan Fuchs
}

Department of Aquatic Environmental Engineering, Institute for Water and River Basin Management, Karlsruhe Institute of Technology, Gotthard-Franz-Str. 3, Bld. 50.31, 76131 Karlsruhe, Germany

\begin{abstract}
Sediment is the main factor that limits the reservoir lifetime. Therefore, sediment classification is an essential tool for planning and operating reservoir management measures. There has been important development in the hydroacoustic classification of lakebed, especially with linear systems. The main restrictions while using linear hydroacoustic systems for lakebed classification are the shallow penetration in high-frequency applications or the low vertical and horizontal resolution when using low frequencies. With the new developments in the area of echo sounders, parametric systems can achieve high penetration while preserving the high vertical and lateral resolution. To investigate the performance of parametric systems, a new lakebed classification approach was implemented by using a SES2000 Compact. The area studied was the Passauna reservoir in Parana State, Brazil. We used the first echo division method for processing the acoustic data combined with sediment core and grab sampling. The two physical parameters investigated, were the share of the finest fraction $(<63 \mu \mathrm{m})$ and wet bulk density (WBD). The results showed a high correlation between the primary frequency of $100 \mathrm{kHz}(166 \mu \mathrm{s}$ pulse length) and the physical parameters. Additionally, a significant correlation was observed with the acoustic parameters at $10 \mathrm{kHz}$ frequency. The best correlating acoustic parameter was Attack/Decay (E1'/E1). The gas presence was found to be an important factor determining the penetration depth of the parametric system and the performance of the classification. The advantages of parametric systems, such small directivity and layering effect, represent the major restrictions in sediment classification applications.
\end{abstract}

\section{INTRODUCTION}

Hydroacoustics is an indispensable tool in mapping and managing of underwater environment. It is the most effective way to probe the lakebed or seabed, as no other energy can propagate in that range. Electromagnetic waves are of limited use, as the water is a highly conductive medium, while traditional single point groundtruthing techniques are subject to constraints regarding the time and costs required for sampling and analysis processes (Lurton, 2002; Caiti et al., 2006). Initially, acoustics was mainly used in sea water applications. With the increasing number of man-made water bodies, however, it is increasingly applied also to shallow waters (lakes and reservoirs).

Lakebed classification is an important decision support tool that improves reservoir lifetime assessment as well as management and personnel cost efficiency of companies or governmental institutions. It provides solutions for engineering applications by differentiating between fine and coarse material in dredging activities or for environmental use by defining the greenhouse gas patterns and quantifying ebullition from water bodies (Ostrovsky et al., 2008).

There is extensive literature dating back to the 1980 s about seabed classification with linear hydroacoustic systems. Until recently, major developments were made in this area (Orlowski. 1984; Chivers, 1990; Anderson and Pacheco, 2011). Today, most systems used for seabed mapping include multi-frequency transducers with a high and a low acoustic frequency. Both linear single-beam (Orlowski, 1984; Chivers, 1990; Heald and Pace, 1996; Siwabessy et al., 1999; Anderson et al., 2008) and multibeam systems (Clarke et al., 1997; Preston et al., 2004) are commonly applied in sediment classification. However, little information is available about applications of parametric sub-bottom profilers in phenomenological approaches of seabed classification. As the parametric systems have some advantages, among others deeper penetration while maintaining a narrow beam, our hypothesis is that a lakebed classification performed with this system can lead to more accurate and detailed results.

Previous studies revealed that the range of frequencies used by parametric systems is not suitable for sediment classification. This happens mainly due to the effect of layering in the backscattered energy (Le Gac et al., 2006). In addition, as stated in the ICES report (Kloser et al., 2002; ICES 2007), the very narrow beam of the system cannot provide the same lakebed discrimination as a wide beam system, which integrates values from large scattering area. Hence, the overall aim of the study was to find out whether a certain parametric system can be used for seabed characterization despite the limitations suggested by literature. As far as we know, usage of parametric systems in traditional seabed classification approaches has not yet been studied extensively. Taking into account that the sediment in the Passauna reservoir consists almost entirely of gassy fine sediment, another question to be answered is the effect of gas voids on the sediment classification results. 
We performed a phenomenological lakebed classification by combining single-point ground truthing measurements with data obtained from a non-linear multifrequency sub-bottom profiler system. For acoustic data acquisition, the parametric sub-bottom profiler SES2000 Compact (Innomar GmbH, Rostock, Germany) was used. The study area was the Passauna reservoir in the state of Paranain Southeast Brazil. The data were acquired during two measuring campaigns in February-March 2016 and October-November 2017.

Then, we related the acoustic parameters from static profiles to the physical parameters from sediment samples. This relation was presented in the form of a mathematical function which was transferred to the dynamic profiles. Based on interpolation, a map with spatial sediment characteristics was created.

\section{METHODS}

\section{Study area}

The reservoir investigated is in the catchment area of the river Passaúna in the Primeiro Planalto Paranaense between parallels $25^{\circ} 15^{\prime}-25^{\circ} 35^{\prime} \mathrm{S}$ and meridians $49^{\circ} 25^{\prime}-49^{\circ} 20^{\prime} \mathrm{W}$. It covers the municipalities of Curitiba, Araucaria, Campo Largo, Campo Magro, and Almirante Tamandaré and is a sub-basin of the Iguaçu River. The Passauna sub-basin area is approximately 150 square kilometers (Saunitti et al., 2004; Carneiro et al., 2016). The Passauna reservoir has an average depth of $9 \mathrm{~m}$ and reaches maximum depths of up to $16.5 \mathrm{~m}$. The reservoir is around $11 \mathrm{~km}$ long. The entrance of the reservoir is a divided water body which is connected to the main body via a channel only. The inlet zone acts as a pre-dam for all suspended particles and contributes to the sedimentation problem of the main body by acting as a first sink area. The sediment was assessed to be in the range of $3.7 \mathrm{hm}^{3}$ and mainly consisted in gassy clay material with sporadic sandy parts mainly near the shore or in areas with high flow velocity (Sotiri and Hilgert, unpublished data). According to the report of the Environmental Institute of Parana State (IAP), the reservoir is ranked in Class III or may be considered moderately degraded in terms of water quality (IAP - Environmental Institute of Paraná State, 2009). The reservoir started operation in 1989 and supplies $30 \%$ of the population of the metropolitan region of Curitiba with drinking water.

\section{Principles of non-linear underwater acoustics}

Parametric echo sounders transmit two signals of slightly different high frequencies at high sound pressures (primary frequencies, e.g. 100 and $110 \mathrm{kHz}$ ). Due to nonlinearities in sound propagation at high pressures, both signals interact and new frequencies result. The so-called secondary frequency (difference of the transmitted frequencies, e.g. $10 \mathrm{kHz}$ ) is low and, hence, can deeply penetrate into the lakebed. The primary frequencies may be used for exact determination of water depth even in situations when the density gradient between water and lakebed is minimal and the acoustic response of the sediment/water interface is weak (Urick, 1982; Wunderlich and Müller, 2003; Wunderlich et al., 2005; Saleh und Rabah, 2016). Another advantage of a parametric echo sounder is the narrow beam. As both primary high frequencies have a narrow beam and, hence, a smaller footprint on the lake bottom, the secondary low frequency also has a narrow beam. A narrow beam means better horizontal resolution and, consequently, better data quality.

The SES 2000 Compact (www.innomar.com/ses2000 compact.php) is an echo sounder which can cover a water depth range from $0.5-400 \mathrm{~m}$. Depending on the sediment type and noise, it penetrates the sediment by up to $400 \mathrm{~m}$. Its layer resolution varies from $1-5 \mathrm{~cm}$. It has a primary frequency band of $85-115 \mathrm{kHz}$ for the acquisition of the bottom track and a secondary low frequency band of 2-22 $\mathrm{kHz}$ for the sub-bottom data. The echo sounder can emit up to $40 \mathrm{pings} / \mathrm{s}$. The system runs on $100-240 \mathrm{~V} \mathrm{AC} / 50-$ $60 \mathrm{~Hz}$ and its power consumption is less than $200 \mathrm{~W}$ according to the manufacturer (Innomar $\mathrm{GmbH}$ ). In order to cover a wide range of frequencies, soundwaves of 4,6 , $10,12,15$, and $100 \mathrm{kHz}$ frequency were used for this campaign. This wide range of frequencies was needed to check which of the frequencies yields a better description of the physical characteristics of the sediment and, consequently, produces the best lakebed classification.

\section{Measuring concept}

The echo sounding measurements included driven profiles that are referred to as dynamic profiles and stable non-moving profiles which are called static. The transducer was mounted on an aluminum vessel with an incidence angle of $0^{\circ}$. The transducer's depth was adjusted between 40-70 $\mathrm{cm}$ depending on the noise level and on the water depth in the measurement area. The whole system was connected to a Leica 1200 DGPS system to reach a positioning precision in the $\mathrm{cm}$ range. Additionally, CTD-profiles (CastAway®-CTD) were taken for sound speed corrections.

For all the dynamic profiles, the same configuration of parameters was used. The frequencies were $6 \mathrm{kHz}, 10$ $\mathrm{kHz}$, and $12 \mathrm{kHz}$ (configurations $\mathrm{B}$ and D). For the best coverage of the reservoir, cross section profiles of the reservoir were recorded. The survey was planned such that an acoustic transect of the reservoir was measured every 50-100 m. Apart from the cross sections, some longitudinal profiles of the reservoir were recorded. In order to prevent motor interference and to optimize horizontal resolution, the vessel speed was limited to 1-2 $\mathrm{m} \mathrm{s}^{-1}$. The measurements were carried out during good 
weather conditions, without wind. Consequently, vertical or lateral motion of the vessel due to waves had no significant influence on the measurements.

The high frequency for all configurations always was $100 \mathrm{kHz}$. However, the pulse length was not always the same and was dependent on the secondary low frequency. For the static measurements at each point, five profiles with different configurations were recorded (Tab. 1). For the static profiles, the sediment was ensonifed for a minimum of 30 seconds in order to have a data set with more than 500 samples for each echogram (Hilgert et al., 2016). Hydroacoustic ensonification was followed by sediment sampling. In this way, the sediment/water interface and the sediment layers remained undisturbed and the recorded acoustic data represented the real conditions of the system. In total, 30 static profiles were measured, of which 23 were core sampled and seven were grab sampled (Fig. 1).

Tab. 1. Sound wave frequencies and the respective pulse lengths.

\begin{tabular}{lccccc} 
& Configuration A & Configuration B & Configuration C & Configuration D & Configuration E \\
Low frequency & $4 \mathrm{kHz}$ & $6 \mathrm{kHz}$ & $10 \mathrm{kHz}$ & $12 \mathrm{kHz}$ & $15 \mathrm{kHz}$ \\
High frequency & $100 \mathrm{kHz}$ & $100 \mathrm{kHz}$ & $100 \mathrm{kHz}$ & $100 \mathrm{kHz}$ & $100 \mathrm{kHz}$ \\
\hline Pulse length & $244 \mu \mathrm{s}$ & $166 \mu \mathrm{s}$ & $97 \mu \mathrm{s}$ & $78 \mu \mathrm{s}$ & $68 \mu \mathrm{s}$ \\
\hline
\end{tabular}
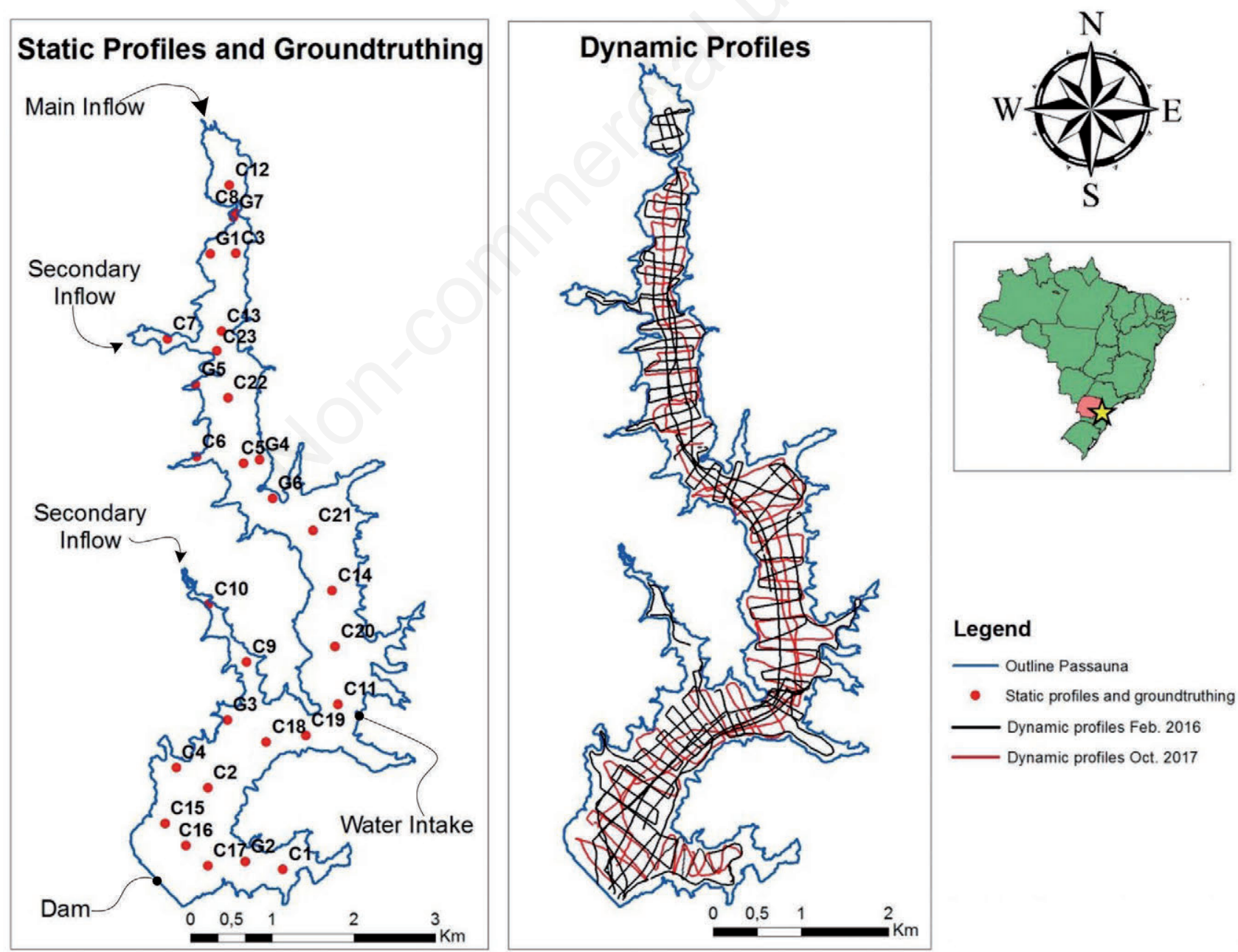

Fig. 1. Static and dynamic profiles measured. 


\section{Ground truthing}

Sediment core sampling was carried out using an Uwitec core sampling device (Niederreiter, 2012). In some cases, the "hammer action" was used for a better sediment penetration, especially at the positions where the sediment was compact or water depth did not allow for a sufficient penetration of the corer. The net weight of the corer was $7 \mathrm{~kg}$; the hammer tool had an additional weight of $7 \mathrm{~kg}$. The sampling tubes were made of transparent PVC and the inner diameter of the tube was $86 \mathrm{~mm}$. All tubes had a length of $84 \mathrm{~cm}$. The corer was used in combination with a manual winch installed on the vessel.

In addition to core sampling, grab samples were taken. Grab sampling generally is less accurate than core sampling, since the sediment structure is disturbed and sampling depth is not clear. During transport to the surface even with closed jars, the fine material may be washed out. The core sample is more reliable in this context, as the material is sealed and no material is washed out. For this reason, the gravity corer was used more often than the grab sampler, even though grab sampling is less timeconsuming.

For sediment processing, the cores were cut in a longitudinal profile. The sample length varied from $15 \mathrm{~cm}$ in the less sedimented areas to $84 \mathrm{~cm}$ in the deep areas. The stratigraphy of each core was visually described for color, structure, texture, gas voids, and organic macroremains, such as vegetation, roots and leaves. The material with similar characteristics was defined a layer and its thickness was measured. Density samples were taken only from the cores. Visually, it was found that the grab samples were highly disturbed and that wet bulk density (WBD) measurements did not reflect in situ density of the sediments before sampling. For the cores, it was verified that the disturbance caused by the liners was minimal and the central part of the $8.6 \mathrm{~cm}$ core was intact. For WBD analysis, a cylinder with a fixed volume of 43.2 $\mathrm{cm}^{3}$ (35 mm diameter and $45 \mathrm{~mm}$ length) was used for extracting the volume sample. A density sample was extracted from all the consolidated sediments layers, while for sediment samples that had high water content the density was assumed $1 \mathrm{~g} \mathrm{~cm}^{-3}$. The sampled material was weighted and density was calculated. From each layer, 300 $\mathrm{g}$ of homogenized material were sampled, if the layer weight was more than $300 \mathrm{~g}$ or the entire layer material was sampled, if the layer was less than $300 \mathrm{~g}$ in weight. The samples were transported to the laboratory, where they were sieved by using distilled water. For granulometry, five sieves were used. The sieves had the following mesh sizes: $2 \mathrm{~mm} ; 500 \mu \mathrm{m} ; 250 \mu \mathrm{m} ; 125 \mu \mathrm{m} ; 63 \mu \mathrm{m}$. After sieving, the samples were dried in $105^{\circ} \mathrm{C}$ for 24 hours. Then, the dry mass of each sample was measured and granulometry was defined. For the core samples, each layer was sieved separately. Final granulometry of each core was determined by summing up the fractions of every layer of the same core and including a weighting factor related to the layer thickness to correct the relative share of each layer. For each station, also a set of acoustic parameters was calculated.

\section{Processing of hydroacoustic data}

All raw data were loaded and sorted in the ISE2 software (www.innomar.com). The sorted raw files were converted to ASCII files. The software used for this purpose was provided by the equipment manufacturer. The exported ASCII files were preprocessed to transform the data structure. During data acquisition, the echo sounder was set to the auto-gain mode and the system automatically adapted the gain factor depending on noise, depth, and sediment type. Consequently, gain correction was necessary in order to bring the data in the same level. The gain level did not only differ between different files, but also varied in the same file. For this reason, as a first step, the gain level of each file was brought to the same level with the use of ISE2. A normalizing factor was calculated for each file and each echogram matrix was divided by a normalizing factor calculated using equation 1 :

$\mathrm{F}=10^{\mathrm{G} / 20}$

where $\mathrm{G}$ is the gain level in $\mathrm{dB}$ and $\mathrm{F}$ is the dimensionless normalizing factor for each echogram. From each profile the acoustic parameters were calculated from each echo envelope and the results were averaged for having only one set of parameters for each static profile.

For lakebed classification, two techniques can be used based on the physical phenomena: one that relies on the coherent reflection of the sound wave at the watersediment interface, and the other, which is based on the backscattering effect inside the sediment (Le Gac et al., 2006).

As one of the advantages of SES2000 is deeper penetration with high resolution, classification was completed by focusing on the backscattering strength of the sediment layers combined also with coherent reflection of the surface layer. For processing the hydroacoustic signal, the measured echo is divided into three phases (Fig. 2) (Orlowski, 1984; Chivers, 1990; Burczynski, 1999; Ostrovsky and Tęgowski, 2010; Anderson and Pacheco, 2011).

Phase 1 - Attack: starts at the moment the pulse reaches the bottom and extends until the time the bottom is reached by the back slope of the pulse. It has a duration of approximately one pulse length and starts at the bottom detection point or water/sediment interface.

Phase 2 - Decay: starts at the end of the attack phase, covers a distance of one incident pulse length from the water sediment interface, and lasts until the front of the 
pulse reaches the boundary of the ideal beam pattern (approximately three pulse lengths).

Phase 3 - Release: lasts until the pulse completely enters the bottom. It is not included in this study, as the calculated algebraic values are irrelevant (Burczynski, 1999).

The terms attack and decay can often be found in literature as hardness and roughness, respectively. They were initially introduced by (Chivers, 1990). The first part of the echo generally describes the surface of the sediments, while the second part or decay phase depends more on the backscattering effect taking place in the sediments. As the backscattering effect is related mainly to the physical roughness of the sediment, it is also called acoustic roughness. The attack phase is estimated by calculating the integral of the echo envelope of the first part of the bottom echo (E1') and the decay phase is estimated by calculating the integral of the second part of the first bottom echo (E1) (Orlowski, 1984). As explained in Ostrovsky and Tęgowski (2010), the numerical ratio of Attack/Decay also provides information about the lakebed composition, which is why this parameter was also taken into account.

First, the acoustic parameters of the static profiles were calculated. As there are a finite number of acoustic samples

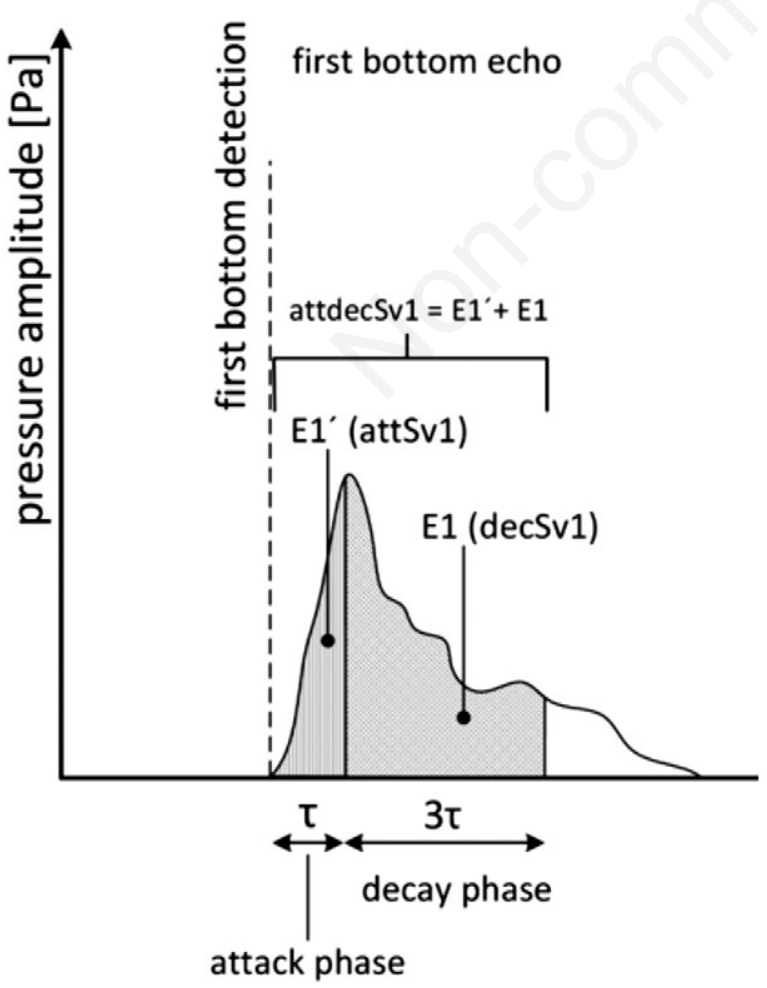

Fig. 2. Division of the echo amplitude. From: Hilgert et al., Adv. Oceanogr. Limnol. 2016;7:5623. in one amplitude curve of sound reflection, each acoustic parameter was calculated as a sum of the trapezoids forming the curve (equations 5 and 6). The finite number of points corresponds to the number of acoustic samples in one envelope of echoes. Depending on the frequency and on the pulse length of the soundwave, the length represented by one acoustic sample varies.

For the calculation of the algebraic values of the parameters, the following approach was applied.

Initially, the acoustic sample length (ASL) was calculated:

$\mathrm{ASL}=\frac{\text { Echogram Range }(m)}{\text { No. of Acoustic Samples }}$

Then, the number of attack and decay samples was determined:

$N_{A}=\frac{T \cdot c}{A S L}$

$N_{D}=3 \cdot N_{A}$

where:

$T$ is the pulse length in [s], $c$ is the sound speed $\left[\mathrm{m} \mathrm{s}^{-1}\right]$, $N_{A}$ is the number of attack samples [pixels], $N_{D}$ is the number of decay samples [pixels], and finally, attack and decay samples were calculated as:

$\operatorname{Attack}\left(E 1^{\prime}\right)=\sum_{i=2}^{N_{A}} \frac{[R(i)+R(i-1)] \cdot T)}{2}$

$\operatorname{Decay}(E 1)=\sum_{i=N A+1}^{N_{D}} \frac{[R(i)+R(i-1)] \cdot T}{2}$

where:

$R(i)$ is the value of reflection at the investigated depth.

Before calculating the acoustic parameters of the dynamic profiles, the water sediment interface was defined for each file in the form of a line. For the bottom line detection, a threshold value was used. The values of the echogram ranged from 0 to 32,650 and the value chosen as the starting point of the sediment was 500 . The value 500 was chosen after a visual assessment of all echograms.

\section{RESULTS}

\section{Physical properties of the sediment}

From single-point ground truthing, the maps in Figs. 3 and 4 were derived. They include information about WBD and granulometry results. WBD was determined to be between $0.7 \mathrm{~g} \mathrm{~cm}^{-3}$ and $1.6 \mathrm{~g} \mathrm{~cm}^{-3}$. The values, however, were rather heterogeneous. In the deep area of the reservoir (8-17 m) WBD was mostly between 0.7-1 $\mathrm{g}$ $\mathrm{cm}^{-3}$. While in the shallow area the WBD had higher values $\left(0.9-1.6 \mathrm{~g} \mathrm{~cm}^{-3}\right)$. The major part of the lakebed consists of unconsolidated material of low density, 
especially in the central part of the reservoir or in the main tributary inflows (C9, C10, C11, or C14 in Fig. 4). The low wet bulk densities are caused mainly by the high share of gas in the sediment samples, which was visible in almost all the retrieved core samples.

As far as granulometry is concerned, 19 out of 30 samples consisted of more than $95 \%$ of the fraction $<63$ $\mu \mathrm{m}$. The samples with high clay-silt fraction were identified mainly in the central area of the reservoir $(\mathrm{C} 2$, $\mathrm{C} 18, \mathrm{C} 15, \mathrm{C} 23)$ or in the large tributary inflow $(\mathrm{C} 9, \mathrm{C} 19)$, while in the areas with high flow velocity $(\mathrm{G} 7, \mathrm{C} 8)$ or in the small tributaries $(\mathrm{C} 6, \mathrm{C} 1)$ the sediment is more sandy. There is coherence between the points with a relatively high WBD and the points with a high sand content (e.g. $\mathrm{C} 1, \mathrm{C} 6$, or $\mathrm{C} 8$ ) which is also presented in Fig. 5.

\section{HYDROACOUSTICS}

Initially, the acoustic parameters were calculated and statistical analysis was performed to check the relationship between the acoustic and physical parameters. All possible parameter combinations were plotted against each other. The Pearson correlation coefficient was considered to be an appropriate method for presenting the data (Taylor, 1990). Some of the high correlation coefficients did not reflect necessarily a proper connection between the acoustic and the physical parameters of the sediment, which is why only the best fit curves will be presented. The Pearson correlation coefficients and their respective significance levels are presented in Tabs. 2 and 3 for both high and low

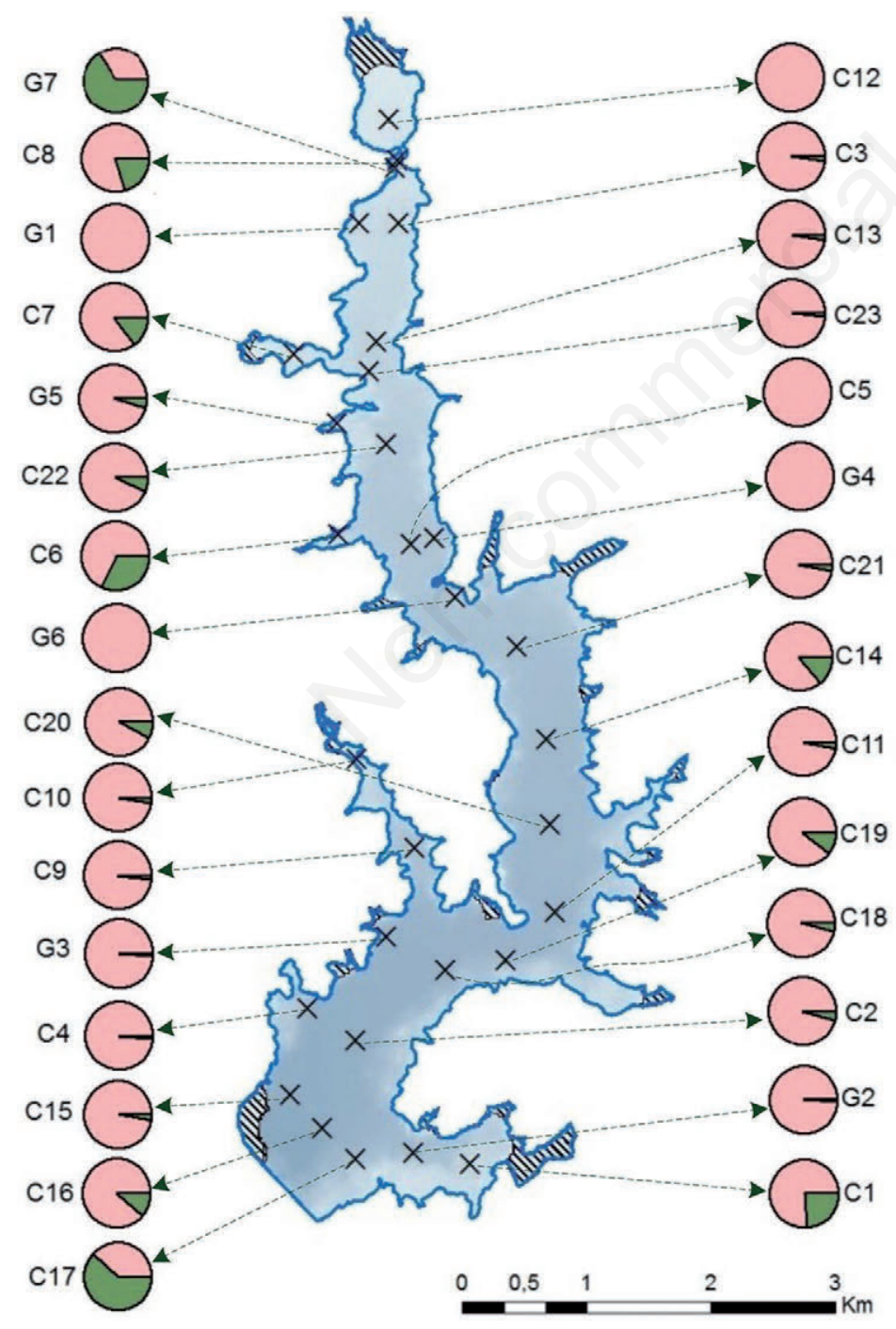

Fig. 3. Granulometry of the core $(\mathrm{C})$ and grab $(\mathrm{G})$ samples.
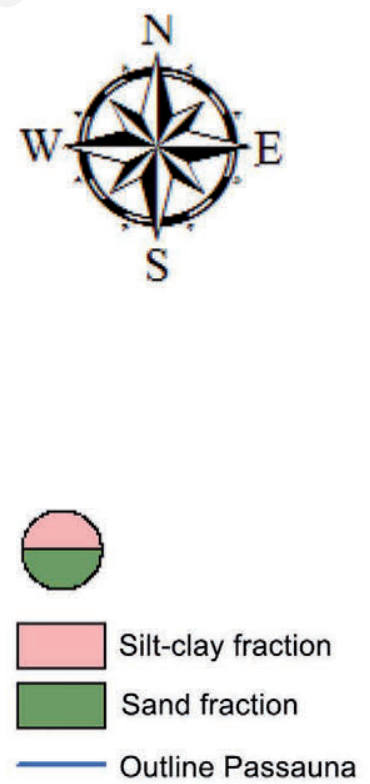

MII. No bathymetric data

$\times$ Static profiles and Groundtruthing

Interpol. depth

(m)

High: 0

Low: -16 


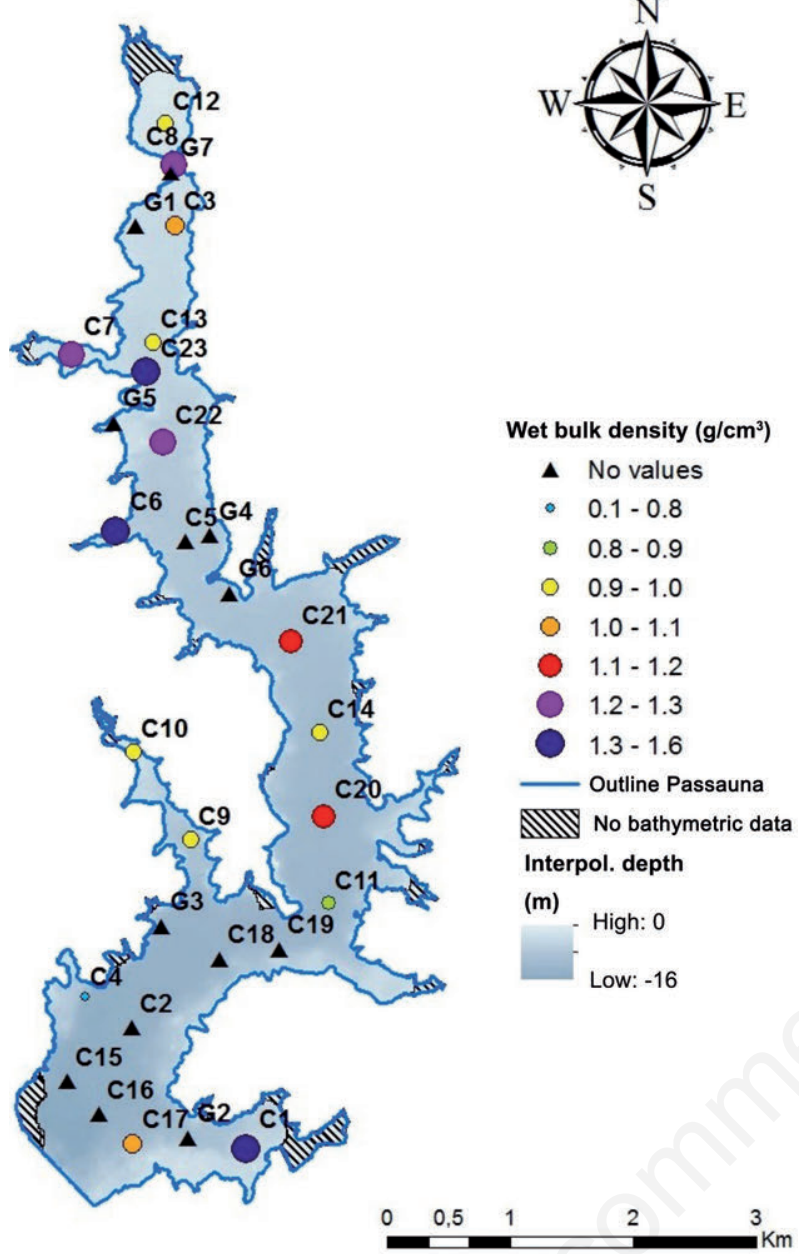

Fig. 4. Wet bulk density of core (C) samples. frequencies. As evident from the Tables, the high frequency yields slightly better results in terms of correlation with the finest fraction share while low frequencies perform better with WBD. Of the high frequencies, $100 \mathrm{kHz}$ with pulse lengths of $244 \mu \mathrm{s}$ and $166 \mu \mathrm{s}$, respectively, yielded better results than the other frequencies. Of the low frequencies, 12 and $10 \mathrm{kHz}$ performed better. The best correlating acoustic parameter is Attack/Decay at high and low frequencies. The parameters derived from $100 \mathrm{kHz} 68 \mu \mathrm{s}$ had no significant correlation with any of the parameters and this may be attributed to the short pulse.

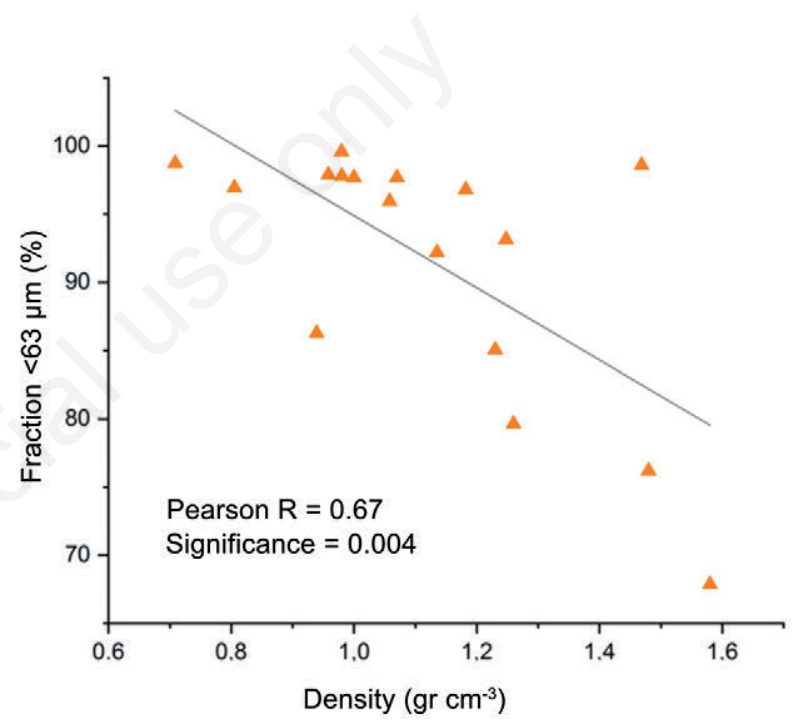

Fig. 5. Relation between density and silt clay fraction of the sediment.

Tab. 2. Pearson correlation coefficient and significance for high frequencies. The most significant correlations are in bold.

\begin{tabular}{|c|c|c|c|c|c|c|c|c|c|c|c|c|c|c|c|c|}
\hline \multirow[t]{2}{*}{ Parameter } & & \multicolumn{3}{|c|}{$244 \mu \mathrm{s}$} & \multicolumn{3}{|c|}{$166 \mu \mathrm{s}$} & \multicolumn{3}{|c|}{$97 \mu \mathrm{s}$} & \multicolumn{3}{|c|}{$78 \mu \mathrm{s}$} & \multicolumn{3}{|c|}{$68 \mu \mathrm{s}$} \\
\hline & & E1' & E1 & E1'/E1 & E1' & E1 & E1'/E1 & E1' & E1 & E1'/E1 & E1' & E1 & E1'/E1 & E1' & E1 & E1'/E1 \\
\hline \multirow[t]{2}{*}{ Density } & Pear & -0.07 & 0.26 & 0.43 & 0.43 & 0.14 & 0.57 & 0.37 & -0.08 & 0.48 & 0.70 & 0.03 & 0.57 & 0.40 & 0.52 & 0.01 \\
\hline & Sign. & 0.79 & 0.32 & 0.09 & 0.08 & 0.58 & 0.02 & 0.14 & 0.75 & 0.05 & 0.02 & 0.92 & 0.07 & 0.12 & 0.03 & 0.96 \\
\hline \multirow[t]{2}{*}{$\%$ Fraction $<63 \mu \mathrm{m}$} & Pearson & -0.09 & 0.23 & -0.67 & -0.24 & 0.28 & -0.68 & 0.11 & 0.16 & 0.04 & 0.28 & 0.13 & 0.23 & 0.18 & 0.05 & 0.12 \\
\hline & Sign. & 0.64 & 0.22 & 0.00 & 0.21 & 0.14 & 0.00 & 0.55 & 0.39 & 0.82 & 0.28 & 0.61 & 0.38 & 0.34 & 0.77 & 0.54 \\
\hline
\end{tabular}

Tab. 3. Pearson correlation coefficient and significance for low frequencies. The most significant correlations are in bold.

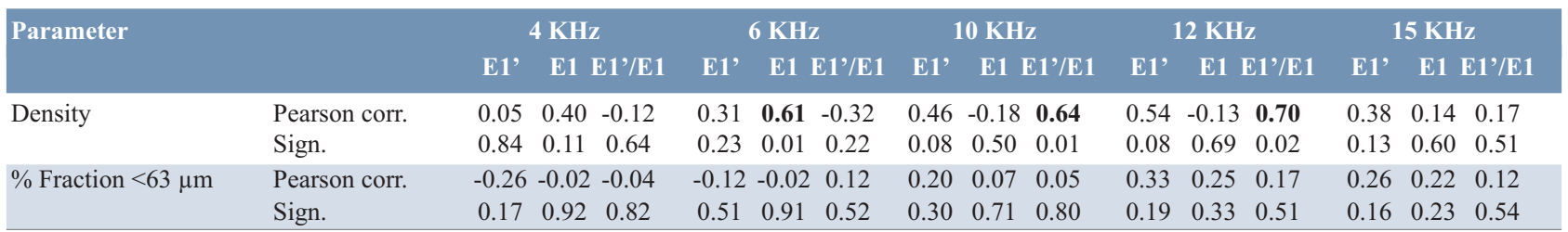


As frequencies of 6,10 , and $12 \mathrm{kHz}$ were used for the dynamic profiles, the focus remained on these 3 frequencies for the static profiles as well. To describe the measured data by a mathematical equation, two scatter plots were created with the $\mathrm{X}$ axis representing the acoustic parameters and the $\mathrm{Y}$ axis showing the WBD (Fig. 6) and finest fraction share (Fig. 7), respectively. For WBD, the best correlation was achieved with the Attack/Decay value of $10 \mathrm{kHz}$. For the regression analysis, the OriginPro software was used and the best curve fit for WBD was found to be the one described by the linear equation 7 with a $\mathrm{R}^{2}=0.37$.

$y=1.01+0.065 \cdot x$

(eq. 7)
For a better assessment of non-linear regression, the residuals were plotted as well. As shown by the residual graph (Fig. 6B), the values reveal no systematic trend in $\mathrm{Y}$ direction and they are spread randomly above and below the zero line (Motulsky und Ransnas, 1987).

For the finest fraction, the procedure was similar. The Attack/Decay calculated from $100 \mathrm{kHz}$ and $166 \mu$ s was the best correlating parameter. The best fitted curve is the one described by eq. 8 with $r^{2}=0.44$. For the finest fraction, the equation is also linear. As obvious from the scatter plot of the residuals, the values obtained for the finest fraction also spread randomly above and below the zero line. Consequently, the $\mathrm{X}$ values do not show any dependency.
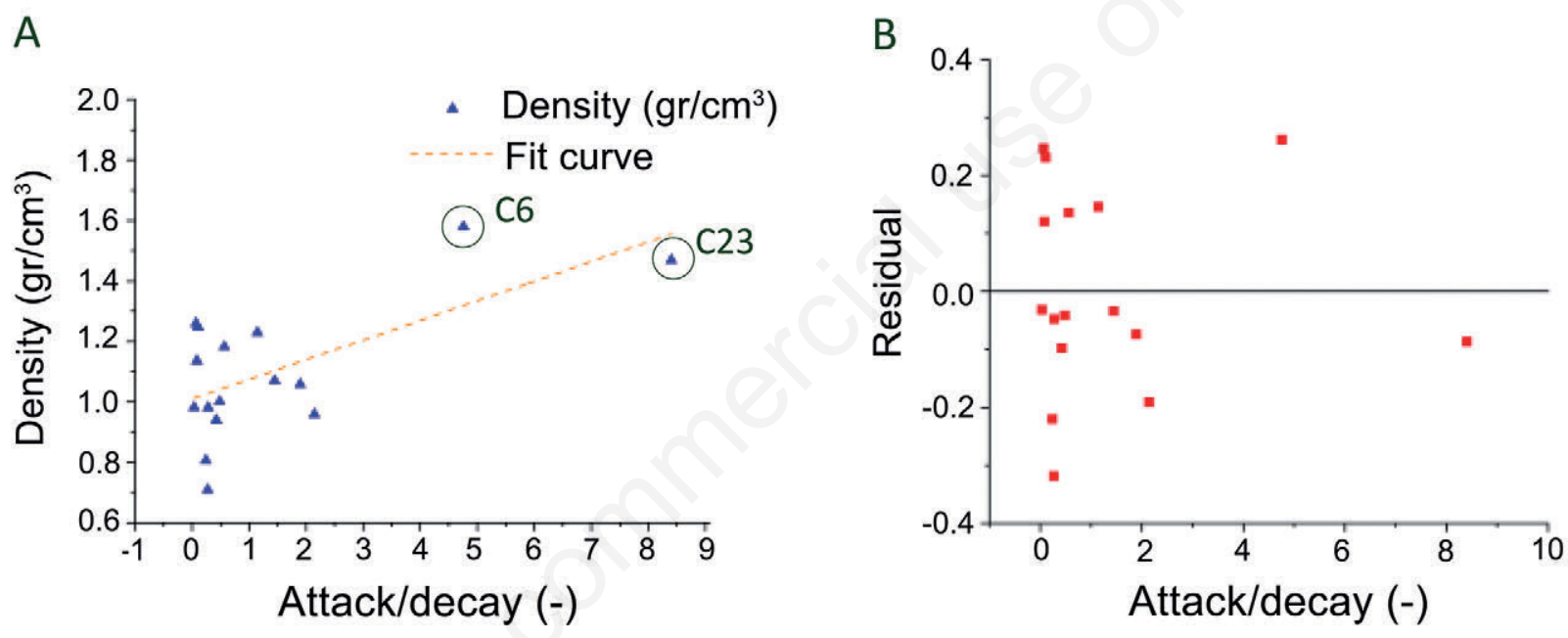

Fig. 6. A) Non-linear regression curve for wet bulk density. B) Residuals of regression.

A

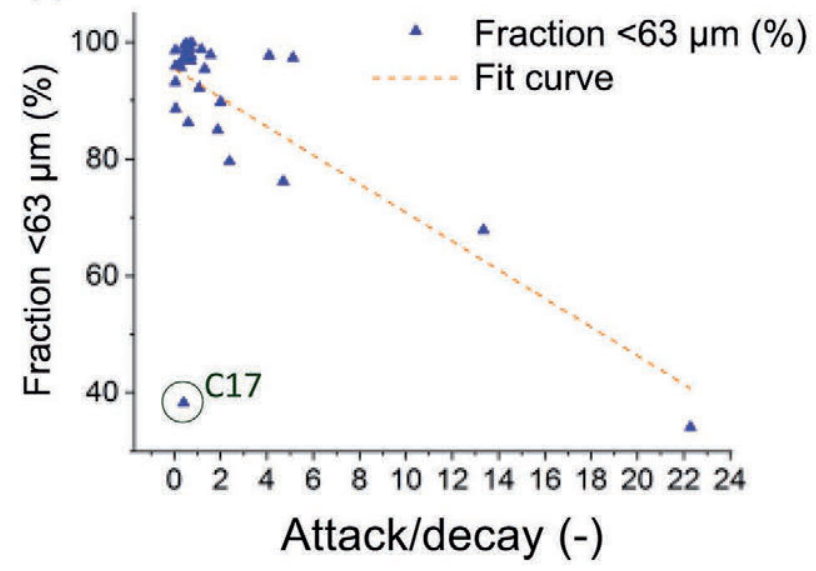

B

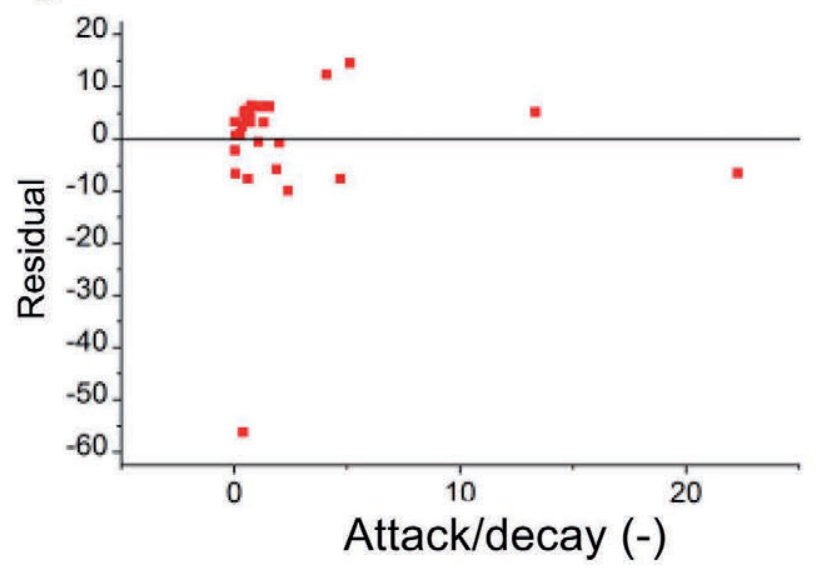

Fig. 7. A) Linear regression curve for the finest fraction share. B) Residuals of the regression. 
$y=95.4-2.454 \cdot x$

(eq. 8)

Equations 7 and 8 were applied by using as $\mathrm{X}$ values the Attack/Decay values calculated from the dynamic profiles, which also had a positioning tag. The points were spatially visualized and spatial distributions of the finest fraction and WBD are presented in Figs. 8 and 9, respectively. Both figures show that the reservoir is covered by unconsolidated material. The finest fraction shares are mostly between $90-95 \%$, while the density is in the range of $1-1.1 \mathrm{~g} \mathrm{~cm}^{-3}$. Fig. 8 clearly shows the different values at the same position, which are calculated from the different transects. This issue is discussed in detail in the section below. As the finest fraction's spatial distribution shows, especially in the February 2016 survey, there is a trend indicating high percentages of $<63$ $\mu \mathrm{m}$ in the central part and small values while approaching the shore. The south part of the reservoir has values of silt-clay fraction of $70-85 \%$ (green color) while the center part has mainly values until $95 \%$ of silt clay fraction (orange color). This is observed only for the finest fraction, but is not visible in the density graph. The density values show a high homogeneity in all the areas of the reservoir.

\section{DISCUSSION}

In this study, a parametric echo sounder was used for lakebed sediment classification. The aim was to investigate whether the advantages of the parametric system result in an improved lakebed or seabed classification compared to "traditional" classification approaches. As the SES2000 Compact emits alternating soundwaves with different frequencies, one research objective was to assess the effect of frequency on the physical parameters and gas presence.

The best correlation coefficients were observed for the low frequencies of 10 and $12 \mathrm{kHz}$. The pulse length also is a deterministic factor, as it represents the ability to resolve
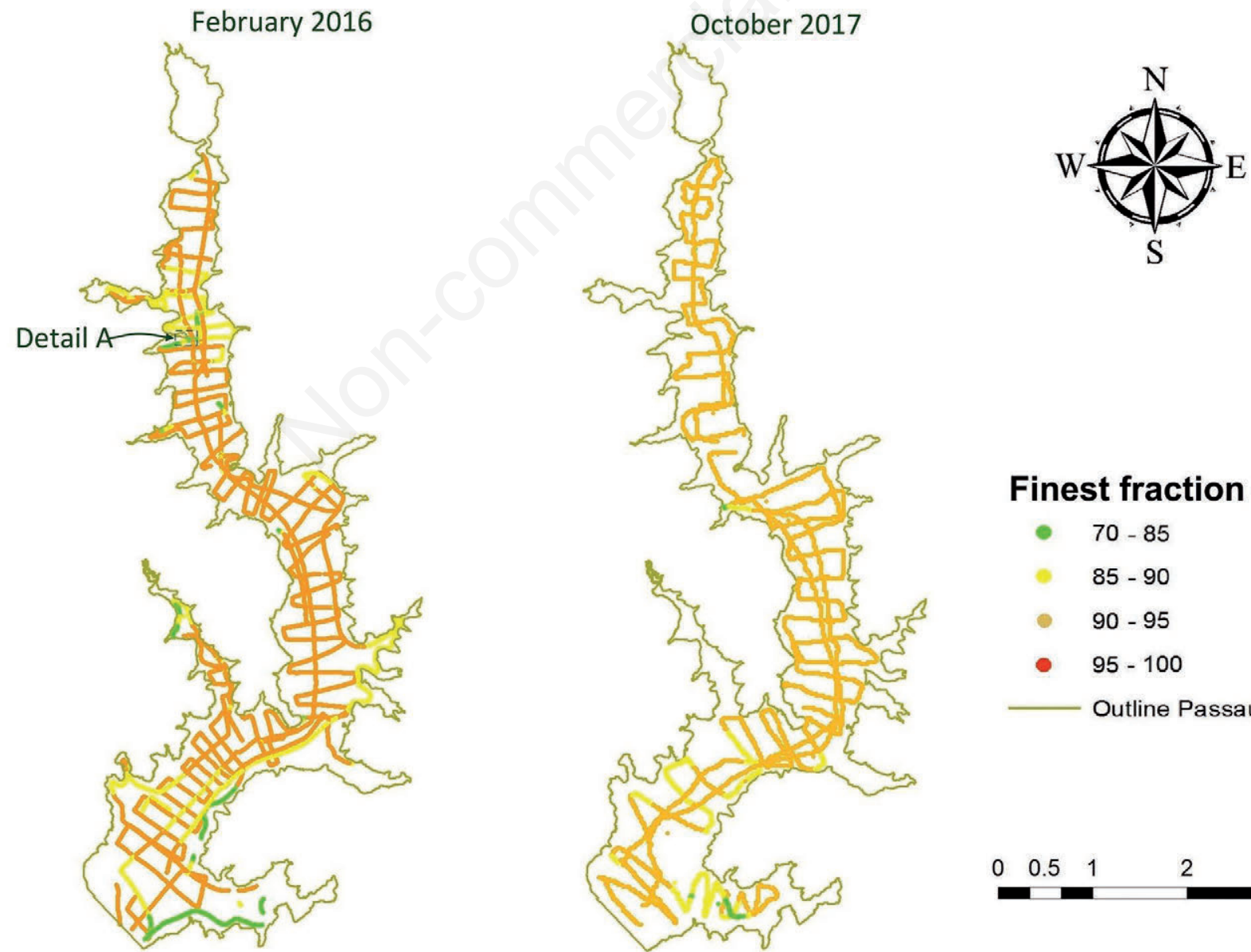

\section{Finest fraction (\%)}

- $70-85$

$85-90$

- $90-95$

- $95-100$

Outline Passauna

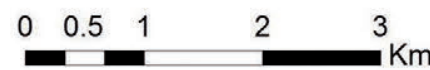

Fig. 8. Visualization of the spatial distribution of fraction $<63 \mu \mathrm{m}$ in $\%$ in both surveys. 
fine-scale heterogeneities within the sediment. Physically, this range of pulse lengths $(166-244 \mu \mathrm{s})$ may provide the optimal combination of soundwave propagation and backscatter strength. The acoustic parameter that performed better is Attack/Decay. The findings obtained by this study confirm also previous findings, that this ratio represents a robust value and allows to accurately detect physical changes of the sediments (BioSonics, 2008), which is especially due to the fact that the values are independent of the normalization factor used in pre-processing. Findings in Lake Kinneret (Ostrovsky und Tęgowski, 2010) or in Lake Elsinore and the San Dieguito Reservoir (Anderson und Pacheco, 2011) also suggest that the acoustic parameter Attack/Decay contains important information on the physical properties of the sediments. In all studies of Lake Kinneret, Lake Elsinore, and the San Dieguito Reservoir (Ostrovsky und Tęgowski, 2010; Anderson und Pacheco, 2011), the fractal dimension calculated from the echo amplitude also correlated significantly with the physical

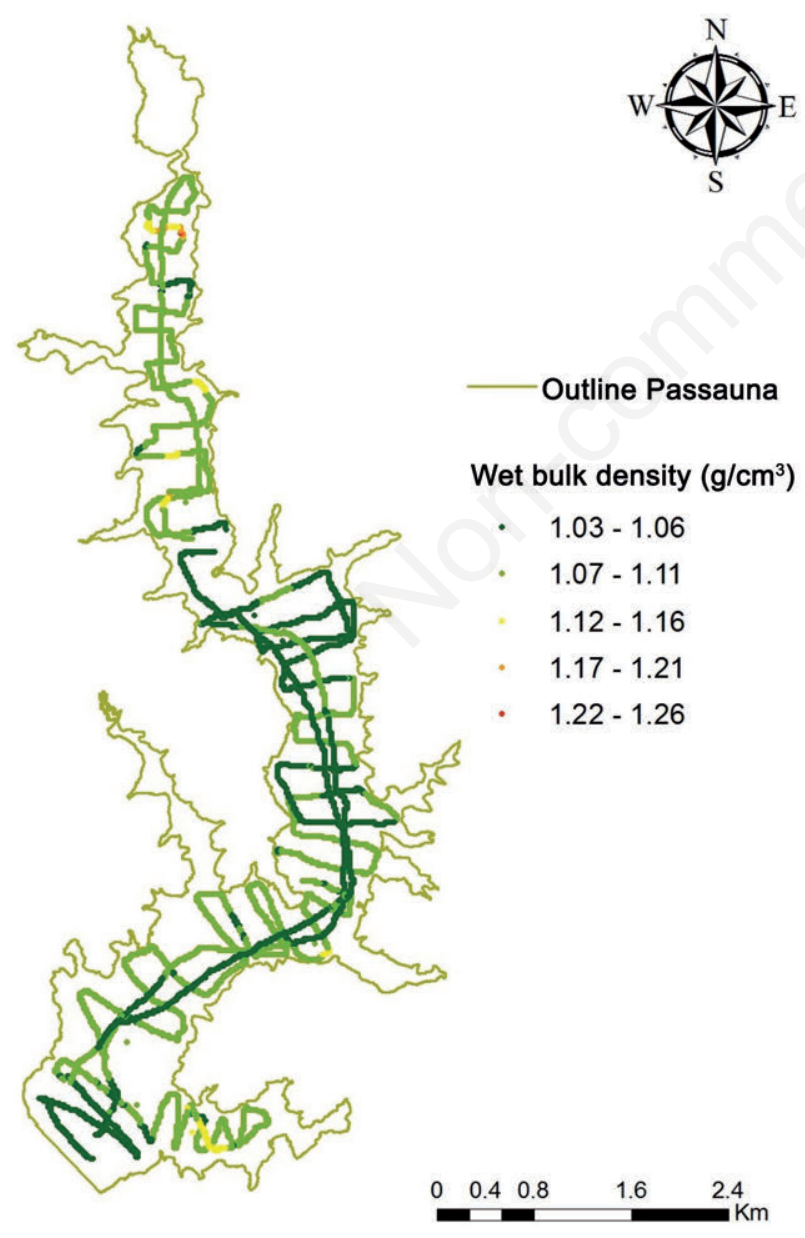

Fig. 9. Visualization of the spatial distribution of density in $\mathrm{g} / \mathrm{cm}^{3}$ in the October 2017 survey. parameters of the sediments. This is not the case for our results obtained from parametric ensonification in the Passauna reservoir. The fractal dimension was calculated using an R script and the correlation coefficients with physical sediment parameters $(\mathrm{r}=-0.18$ to -0.31 for density and $r=-0.08$ to 0.02 for $\%$ fraction $<63 \mu \mathrm{m}$ ) did not reveal any high correlating values. The fractal dimension had no correlation to any of the parameters and could not be used for further regression analysis.

The correlation of Attack/Decay at $10 \mathrm{kHz}$ and WBD is a low correlation though it was the highest of the correlation factors. In Fig. 6, a large number of points are concentrated on the left, including the ratio Attack/Decay between 0 and 2 and only two points in the right part. High Attack/Decay values indicate a high coherent reflection. In case of $\mathrm{C} 23$ and $\mathrm{C} 6$, the very strong attack value may be attributed to the high gas presence in the first layer and the curve can be misleading. This is also confirmed by the results of the dynamic profiles, where the maximum value of the Attack/Decay value at $10 \mathrm{kHz}$ was 3.44. In the regression analysis, the maximum Attack/Decay value reaches 8.5 , which is more than twice the value calculated from the dynamic profiles.

For the finest fraction, the correlation with the Attack/Decay value at $100 \mathrm{kHz}$ and $166 \mu$ s pulse length was better. Point $\mathrm{C} 17$ in the graph seems to be an exception compared to the other points. This may be due to various reasons. As for points $\mathrm{C} 6$ and $\mathrm{C} 23$ in Fig. 6, it may be an artifact, indicating gas presence in the deep part of the sediment or a very soft material in the first layer (Fig. 10). The physical properties of the core sample however, do not prove this issue. Another possibility is the error in the measuring procedure due to lateral movement of the boat or noise caused by the external factors such as motor.

The finest fraction exhibits a negative correlation with the Attack/Decay value and this indicates a higher significance of the Decay parameter for the whole ratio. A high finest fraction share would have a low Attack/Decay value, which means that the hardness of the sediment is low and the roughness (volume backscatter strength) is high. Interpretation of the density and finest fraction share curve is in agreement with the findings of Jackson et al. (1986), who stated that high surface reflections are common for a sandy seabed and high backscatter strengths are characteristic of soft silty sediments (Jackson and Briggs, 1992; Jackson et al., 1986). There is a shallow gas front in almost the entire reservoir, which leads to a consumption or reflectance of the echo energy within the first couple of meters. There is no deeper penetration, which is common in the presence of gassy layers in sub-bottom profiling (Schneider von Deimling et al., 2013; Tóth et al., 2014, 2015). As the principle of the parametric systems used is non-linear 
acoustics, they may have a low generation efficiency and low transmitted echo levels (Lurton X. 2002). This is confirmed by Fig. 11, where the range of reflection reaches values of up to 3500 for the sediment only, while the maximum value for the system is 37,500 . The low efficiency is amplified by the presence of gas that restricts sound penetration to a couple of meters only. This might result in restrictions of applications of the parametric echo sounder in reservoir sediment magnitude assessment, especially in the tropic and equatorial regions, where the formation of free gas in sediment voids is rather large (Toth et al., 2015).

The parametric systems focus mainly on coherent reflection between the sediment layers rather than on

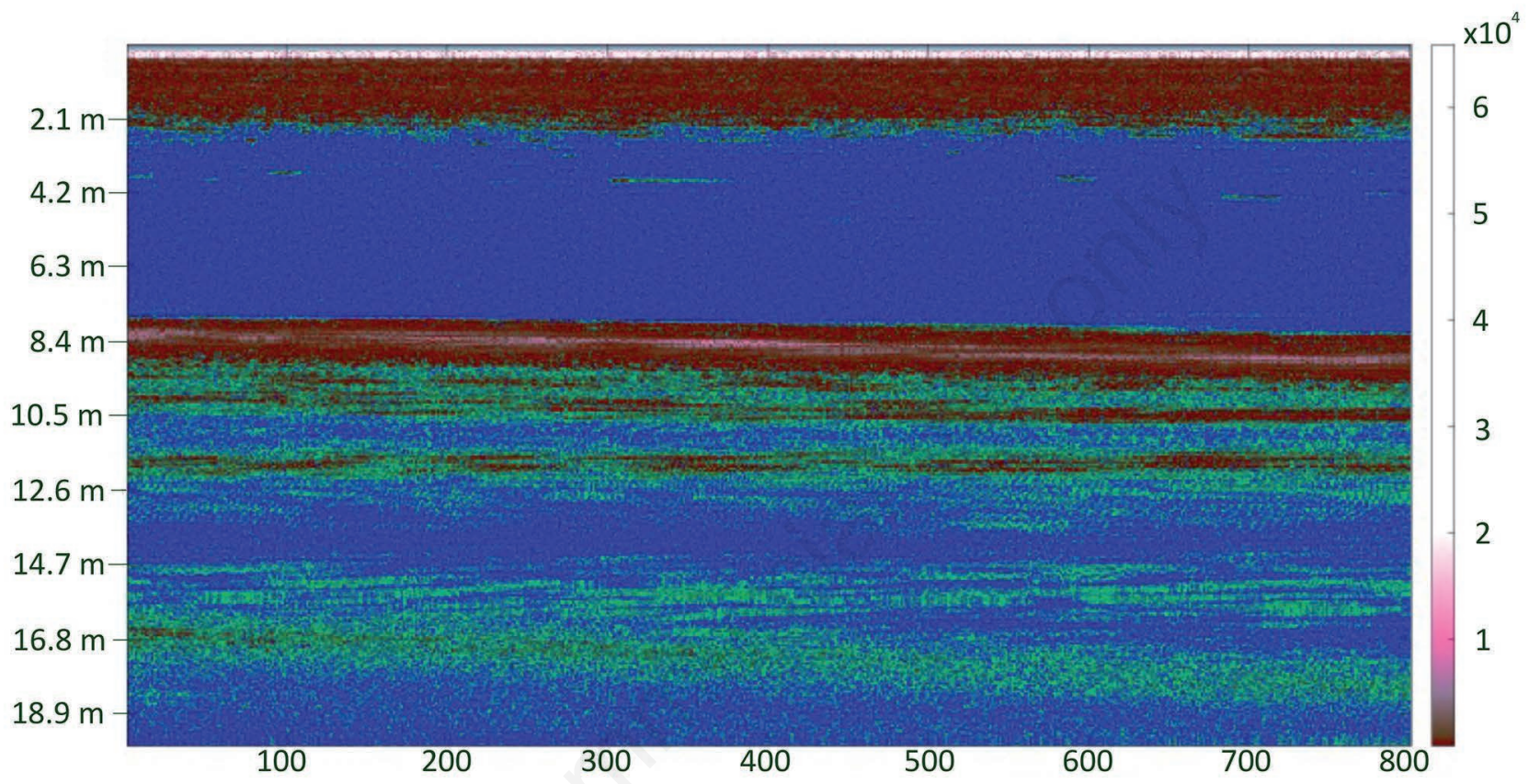

Fig. 10. Visualization of a static profile with 800 pings. On the left side, the depth is shown, while the color bar on the right presents the intensity of the reflection.

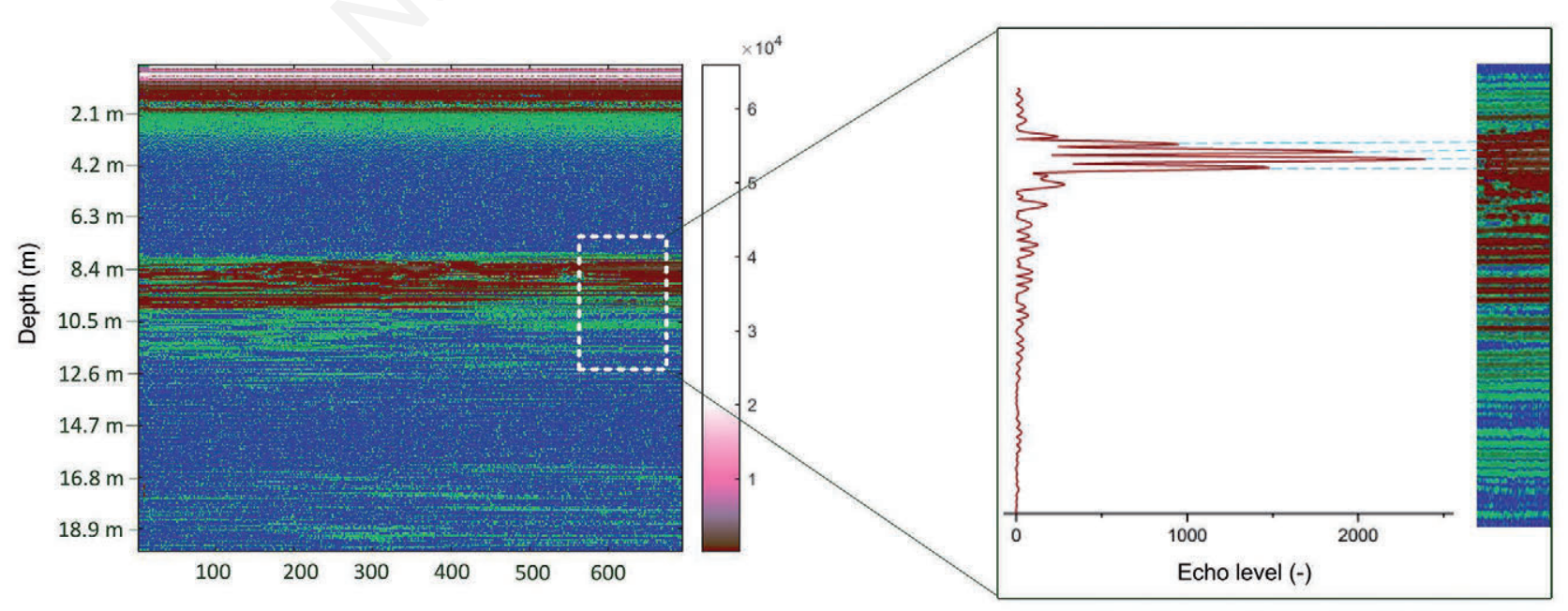

Pings

Fig. 11. Shallow penetration and layering in a profile recorded at $4 \mathrm{kHz}$. 
volume backscatter strength of the layer itself. Effects of layering caused by the acoustic impedance discontinuities might also have a significant impact on the calculated acoustic parameters and backscattered energy (Fig. 11). Other studies state that the effect of layering can be misleading in sediment classification with parametric frequencies (Holland, 2002; Le Gac et al., 2006). Hence, it remains unclear whether the above-mentioned points $(\mathrm{C} 23, \mathrm{C} 6$, or C8) are the only points in the graph that are affected by the presence of layers or gas or the effect of layering, as the physical parameters of the cores present no clear information, due to the restricted length or high homogeneity.

The Decay calculated at $6 \mathrm{kHz}$, also represents a satisfying correlation coefficient with density (Pearson$\mathrm{r}=0.61$ ). However, the coefficient is positive contrary to the published literature which states that decay values should have a negative correlation with density (Hilgert et al., 2016). As explained before, we assume the layering of the echogram to be the dominant factor when calculating the acoustic parameters. Inconsistencies after extrapolating the equations to the driven lines may be due to various reasons. As shown in Fig. 12, the overlapping points at some positions do not show the same characteristics. The Figure presents the same points from two different directions (detail A in Fig. 8). The slope in relation to the driven direction obviously represents an important influence on lakebed classification. The slope may be crucial, as it is directly linked to the incidence angle and, hence, to the footprint of the soundwave. In case of narrow footprints and a heterogeneous lakebed, even smallest changes in the direction of the transducer due to external factors may cause a significant discrepancy in the results. Depending on the direction of sounding, two different points with the same GPS tag could be measured. According to the findings of Szalay and MacConaughey (2002), slopes of more than $8^{\circ}$ have a significant influence on the results. The investigated parts (Fig. 12) are exceptionally steep and, hence, cause a very strong direction-dependent alteration of the backscatter intensity. The auto-gain correction included in the data set might also be an important factor influencing the results. Additional work will be needed to test the influence of these or other parameters on the applicability of the calculated regression curves to dynamic profiles.

In non-gassy sediment the sub-bottom profiler can reach many meters of penetration, and the doubt emerges whether the methodology can be derived by using sediment core samples with length until a maximum of $84 \mathrm{~cm}$. However, as presented in Fig. 11 the relevant penetration in Passauna is confined to the first 1-2 m. This happens mainly due to the high volumetric gas content that limits the wave attenuation. From our measurements (unpublished data), the gas content in the first $30 \mathrm{~cm}$ of the sediment is in the range of $2-15 \%$. With such high values of gas content the acoustic impedance of the sediment matrix is expected to be high and the sound penetration extremely shallow. The range of the sound penetration is similar to the range of the core samples, which allows for implementing the methodology and using the ground truthing data for validation.

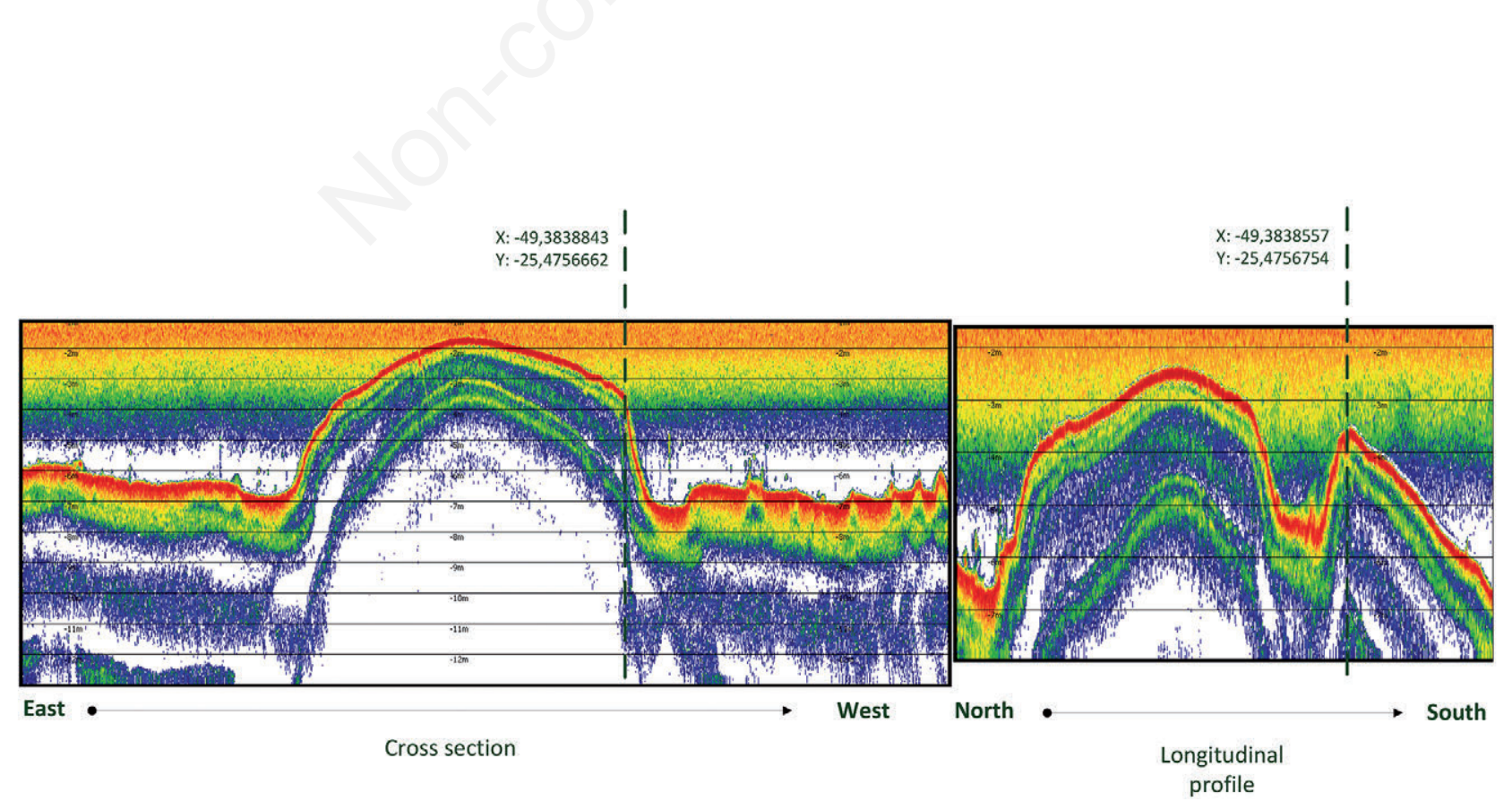

Fig. 12. Detail A from Fig. 8. Crossing lines. 


\section{CONCLUSIONS}

The sub-bottom profiler has clear advantages over the linear systems. Its small opening angle and its deep penetration in the sediment represent unique opportunities for sediment mass assessment. In this regard the system is already well established. To our knowledge there have been no clear tries to classify the sediment by using this type of echo sounder. A successful attempt would not only mean an accurate sediment volume detection but also a precise characterization of sediment type. If we take the example of dredging, specific and high resolution information of sediment thickness and type could help in rigorous planning of the activities, minimizing personnel and equipment costs as well as reducing follow up errors. However, the advantages of the subbottom profiler seem to cause major constraints in sediment classification applications. The primary high frequencies were found to result in a better classification performance in general, while the low frequencies that penetrated deeper showed no satisfying connection to the physical parameters of the sediment. Primary soundwaves at a frequency of $100 \mathrm{kHz}$ correlated better than the parametric soundwaves. At high frequencies, the problem consisted in extrapolating the fit curve to the dynamic profiles rather than in the correlation itself. Even though the opening angle of the system was not optimal for sediment classification applications, the correlation coefficients of physical and acoustic parameters were rather high in some of the cases investigated. The opening angle, however, also represents a restriction for the driven profiles due to the high slopes of the lakebed and small footprint.

Gas presence interference, a well-known phenomenon in hydro acoustics, also is a limiting factor in case of the parametric system. The combination of gas with the layering of the sediment at low frequencies is another restriction in calculating proper acoustic backscatter parameters. Furthermore, Passauna reservoir has only limited heterogeneities in sediment composition, since most of the lakebed is covered by very fine-grained, organic-rich material. This creates challenging conditions for testing the presented methodology.

The parametric system is a powerful tool that provides accurate solutions for the estimation of sediment magnitude and sediment vertical differentiation. Literature suggests that it can be used with total reliability for sediment volumetric analysis. Regarding sediment classification, a suggestion would be the parallel usage of a linear hydroacoustic system for sediment classification, in order to complement the results obtained from the parametric system.

\section{ACKNOWLEDGMENTS}

This research was funded by the German Academic Exchange Service (DAAD) within Project 57203877 and the German Federal Ministry of Education and Research within Grant 02WGR1431A. We would like to cordially thank Sanepar for logistical support and access to the reservoir. We also thank the research team from DHS and DEA, UFPR and especially Prof. Tobias Bleninger, Prof. Cristovão Vicente Scapulatempo Fernandes and Mauricio B. Scheer from Sanepar team. Special thanks go to the staff of the laboratory and the technical staff of DHS, who supported our measurement campaign. We also thank Innomar $\mathrm{GmbH}$ for the technical support and their useful comments to this study.

\section{Corresponding author: klajdi.sotiri@kit.edu}

Key words: Non-linear acoustics; parametric echo sounder; reservoir management; sediment classification; sediment physical properties.

Received: 27 November 2018.

Accepted: 16 April 2019.

This work is licensed under a Creative Commons Attribution NonCommercial 4.0 License (CC BY-NC 4.0).

${ }^{\circ}$ Copyright: the Author(s), 2019

Licensee PAGEPress, Italy

Advances in Oceanography and Limnology, 2019; 10:7953

DOI: 10.4081/aiol.2019.7953

\section{REFERENCES}

Anderson JT, van Holliday D, Kloser R, Reid DG, Simard Y, 2008. Acoustic seabed classification. Current practice and future directions. ICES J. Mar. Sci. 65:1004-1011.

Anderson MA, Pacheco P. 2011. Characterization of bottom sediments in lakes using hydroacoustic methods and comparison with laboratory measurements. Water Res. 45:4399-4408.

BioSonics Inc., 2008. User Guide: Visual Bottom Typer 1.10. BioSonics Inc., Seattle.

Burczynski J, 1999. Bottom classification. BioSonics Inc.

Caiti A, Chapmann R, Hermand JP, Jesus SM, 2006. Acoustic sensing techniques for the shallow water environment. Springer, Dordrecht: 336 pp.

Carneiro C, Kelderman P, Irvine K, 2016. Assessment of phosphorus sediment-water exchange through water and mass budget in Passaúna Reservoir (Paraná State, Brazil). Environ. Earth Sci. 75:564.

Chivers RC, 1990. New acoustic processing for underway surveying. Hydrogr. J. 56:9-17.

Clarke J, Hughes E, Danforth BW, Valentine P, 1997. Areal 
seabed classification using backscatter angular response at 95 kHz, p. 243-245. In: Proceedings of the Conference High Frequency Acoustics in Shallow Water, Lerici, Italy. Nato Saclant Centre.

Heald GJ, Pace NG, editors. 1996. An analysis of 1st and 2nd backscatter for seabed classification, p. 649-654. In: Proceedings 3rd European Conference on Underwater Acoustics, Heraklion.

Hilgert S, Wagner A, Kiemle L, Fuchs S, 2016. Investigation of echo sounding parameters for the characterisation of bottom sediments in a sub-tropical reservoir. Adv. Oceanogr. Limnol. 7:5623.

Holland CW, 2002. Coupled scattering and reflection measurements in shallow water. IEEE J. Oceanic Eng. 27:454-470.

IAP (Environmental Institute of Paraná State), 2009. [Monitoramento da qualidade das águas dos reservatórios do estado do Paraná, no período de 2005 a 2008].[Report in Spanish]. Environmental Institute of Paraná State, Curitiba. Anderson JT, Holliday DV, Kloser RJ, Reid D, Simard Y. 2007. Acoustic seabed classification of marine physical and biological landscapes. ICES cooperative research report No. 286. ICES, Copenhagen: 186

Jackson DR, Briggs KB, 1992. High-frequency bottom backscattering. Roughness versus sediment volume scattering. J. Acoust. Soc. Am. 92:962-977.

Jackson DR, Winebrenner DP, Ishimaru A, 1986. Application of the composite roughness model to high-frequency bottom backscattering. J. Acoust. Soc. Am. 79:1410-1422.

Kloser RJ, Keith G, Ryan T, Williams A, Penrose J, 2002. Seabed biotope characterisation in deep water-initial evaluation of single and multi-beam acoustics, p. 81-88. In: Proceedings of the 6th European Conference on Underwater Acoustics, Gdańsk.

Le Gac JC, Steéphan Y, Garlan T, Weber N, 2006. On the assessment of geoacoustic parameters in shallow water environments, p. 1-15. In: A. Caiti, N.R. Chapman, J.P. Hermand and S.M. Jesus (eds.), Acoustic sensing techniques for the shallow water environment: Inversion methods and experiments. Springer, Dordrecht.

Lurton X, 2002. An introduction to underwater acoustics. Springer, Berlin: 347 pp.

Motulsky HJ, Ransnas LA, 1987. Fitting curves to data using nonlinear regression. A practical and nonmathematical review. FASEB J. 1:365-374.

Niederreiter R, 2012. Uwitech sampling equipments. Available from www.uwitec.at/html/frame.html

Orlowski A, 1984. Application of multiple echoes energy measurement for evaluation of bottom type. Oceanologia 19:61-78.
Ostrovsky I, McGinnis DF, Lapidus L, Eckert W. 2008. Quantifying gas ebullition with echosounder. The role of methane transport by bubbles in a medium-sized lake. Limnol. Oceanogr.-Meth. 6:105-118.

Ostrovsky I, Tęgowski J, 2010. Hydroacoustic analysis of spatial and temporal variability of bottom sediment characteristics in Lake Kinneret in relation to water level fluctuation. GeoMar. Lett. 30:261-269.

Preston JM, Christney AC, Beran LS, Collins WT, 2004. Statistical seabed segmentation-from images and echoes to objective clustering, p. 813-818. In: Proceedings 7th European Conference on Underwater Acoustics, Delft.

Saleh M, Rabah M, 2016. Seabed sub-bottom sediment classification using parametric sub-bottom profiler. NRIAG J. Astron. Geophys. 5:87-95.

Saunitti RM, Fernandes LA, Bittencourt AVL, 2004. [Estudo do assoreamento do reservatório da barragem do rio PassaúnaCuritiba-PR].[Article in Portuguese]. Boletim Paranaense Geociências 54. Doi: http://dx.doi.org/10.5380/geo.v54i0. 4253

Schneider von Deimling J, Weinrebe W, Tóth Z, Fossing H, Endler R, Rehder G, Spieß V, 2013. A low frequency multibeam assessment. Spatial mapping of shallow gas by enhanced penetration and angular response anomaly. Mar. Petrol. Geol. 44:217-222.

Siwabessy J, Penrose J, Kloser RJ, Fox DR, 1999. Seabed habitat classification. In: Proceedings International Conference on High Resolution Surveys in Shallow Water. Sydney.

Szalay PG, McConnaughey RA. 2002, The effect of slope and vessel speed on the performance of a single beam acoustic seabed classification system. Fish. Res. 56:99-112.

Taylor R, 1990. Interpretation of the Correlation Coefficient. A basic review. J. Diagn. Med. Sonog. 6:35-39.

Tóth Z, Spiess V, Keil H, 2015. Frequency dependence in seismoacoustic imaging of shallow free gas due to gas bubble resonance. JGR Solid Earth 120:8056-8072.

Tóth Z, Spiess V, Mogollón JM, Jensen JB, 2014. Estimating the free gas content in Baltic Sea sediments using compressional wave velocity from marine seismic data. JGR Solid Earth 119:8577-8593.

Urick RJ, 1982. Sound propagation in the sea. Peninsula Publishing, Los Altos: 226 pp.

Wunderlich J, Müller S, 2003. High-resolution sub-bottom profiling using parametric acoustics. International Ocean Systems 7:6-11.

Wunderlich J, Wendt G, Müller S. 2005. High-resolution echosounding and detection of embedded archaeological objects with nonlinear sub-bottom profilers. Mar. Geophys. Res. 26:123-133. 